\title{
Effects of Flavonoids Extracted from the Diaphragma of Walnut (Juglans regia L.) on Spatial Memory of the Aged-model Mice
}

\author{
Yikun Liu a , Jie Gao b, Yue Dong, Ping Shao, Liyuan Tian, Yu Wang and \\ Huiping Liu c, * \\ College of Food Engineering and Biotechnology, Tianjin University of Science and Technology, \\ Tianjin, China. \\ aliuyikun0907@sina.com, b645667762@qq.com, cliuhuiping111@163.com
}

\begin{abstract}
Flavonoids from the diaphragma of walnut has good antioxidant capacity. In this study, the D-galactose induced aging mice were gavaged by flavonoids extracted from walnuts diaphragm with three different doses (low, medium and high).Results showed that D-galactose can reduce the content of unsaturated fatty acids in the brain, however, compared with the model groups, the content of unsaturated fatty acids in the brain was significantly increased in the low-dose group, medium-dose group and high-dose group, especially the content of EPA and DHA, which can inhibit the aging of mice. The biopsy of brain tissue showed that the diaphragma of walnut have some protective effects on brain tissue.
\end{abstract}

Keywords: Flavonoids; Diaphragma of walnut; Antioxidant activity; Memory.

\section{Introduction}

The walnut (Juglans regia L.) is a tree traditionally cultivated for its valuable wood and fruits. The walnut seed is a nut of high economic interest to the food industry and is globally popular and valued for its nutritional, healthy and sensory attributes. There are a total of 9 genera and 71 species of tree species of Walnut Branch ( Juglandaceae ) exist in the world. Most of them distribute in the northern hemisphere, including Asia, Europe, North America, there are 7 genera and 27 species in China. There are more than 60 countries in the world producing Walnut: Asia, including China, Korea, Japan; In Europe, there are more than 20 countries,including France, Iran, Italy, Poland, the UK. Walnut resources are abundant in China. Diaphragma of walnut is an agro-forest waste generated in the walnut harvest that could be valued as a source of natural compounds with antioxidant.

Flavonoids, found in a variety of fruits, vegetables and beverages, had been recognized as promising plant-based bioactives influencing different aspects of synaptic plasticity, thus resulting in improvements in memory and learning in both animals and humans.

In this study, diaphragma of walnut was used as raw material to extract flavonoids compounds. Its antioxidant activity was also studied. The aim of the study was to provide theoretical basis for the development and utilization of diaphragma of walnut.

\section{Materials and methods}

\subsection{Preparation of Flavonoids from Diaphragma of Walnut}

Ethanol (analytical grade) was purchased from Tianjin Institute of chemical reagent, China. The flavonoids were extracted in the condition of $50 \%$ ethanol, solid-liquid ratio $1: 40$, at $50{ }^{\circ} \mathrm{C}$ for $40 \mathrm{~min}$.

\subsection{Animal Experiment}

60 male, 8 weeks old Kunming mice at SPF level weighed $18 \pm 2 \mathrm{~g}$ from Academy of Military Medicine Experimental Animal Centre (Beijing, China) were used for experiments in vivo. The animals were housed in clean animal rooms of Tianjin University of Science and Technology. The environmental facilities certificate number is SYXK (Tianjin) 2006-0005, and the mice were housed in groups of 10 per cage at a temperature of $24 \pm 1{ }^{\circ} \mathrm{C}$, a $12 \mathrm{~h}$ light-dark cycle starting at 8:00 AM, and a humidity of $60 \%$ for 1 week before the experiment. Food and water were provided ad libitum.FDW 
was configured with distilled water, in accordance with the following intragastric administration of drugs for 8 weeks.

After one week, they were randomly divided into normal group, model group, FDW-low (50 $\mathrm{mg} / \mathrm{kg} \mathrm{bw})$, medium (100 mg/kg bw) and high-dose groups (200 mg/kg bw) and positive control group (VE solution $(50 \mathrm{mg} / \mathrm{kg} \mathrm{bw})$ ). In addition to the normal group, the other groups have been D-galactose neck injection process $(120 \mathrm{mg} / \mathrm{kg} \mathrm{bw})$. D-gal was purchased from Amresco Inc. (Solon, $\mathrm{OH}, \mathrm{U}$. S. A.); Mice from normal and model group were given equal volume of normal saline. During this period, they were weighed every 7 days, then adjusted the injected or intragastric doses according to the mouse body weight.

After completion of the experiments, the animals were dislocated cervical vertebrae to death. Then, the brain tissues were stored and fixed in formalin at $-80{ }^{\circ} \mathrm{C}$ immediately for a histological assay.

\subsection{Morris Water Maze Test}

After the completion of the model building, each group of mice were conducted to the Morris water maze experiment.Water maze consists four parts:the circular pool, video cameras, video capture devices, and data analysis system. Laboratory mice were forced to swim in the pool with the water stained by India ink during the experiments. Observing and recording the time needed for mice to find the platform hidden underwater, swimming trajectory and state, the strategy they used, then analysed and inferred the ability of learning and memory in mice and spatial orientation. Experiments were conducted with the water temperature of $25 \pm 2{ }^{\circ} \mathrm{C}$, in a quiet, dark room. The experiment is divided into two parts: navigation experiment, space exploration experiment.

Pre-training: A visible platform $(2.5 \mathrm{~cm}$ above water surface) was placed in water so that the animal was able to see it. Mice first received a training trial from each of the four starting locations of the tank (N, S, E, W). Before the first trial, mice were placed on the platform for $20 \mathrm{~s}$. Following this, they were placed in the water at the designated starting location. Each rat was allowed $60 \mathrm{~s}$ to find the platform and climb onto it. After $60 \mathrm{~s}$, mice were gently guided to the platform. The time required for animals to reach the platform was recorded (in seconds) with a maximum of $60 \mathrm{~s}$ for mice that failed to find the platform. Mice were left on the platform for $10 \mathrm{~s}$ after they found it in each trial.

Probe trial: The platform was removed from the tank. Mice then underwent 4 trials, with 1 starting at each pole of the tank. Swimming time and distance spent in the quadrant of the tank where the platform was previously located was recorded as a percent of the total amount in each trial. The number of times that each rat crossed the previous location of the platform was also documented.

Pretreatment of mice brain: After the dislocated cervical vertebrae to death, brain tissue was dissected, then washed away the residual blood in $0.9 \%$ saline, ground into $10 \%$ tissue homogenate fluid using a tissue homogenate tube, centrifuged at $4{ }^{\circ} \mathrm{C}, 3500 \mathrm{r} / \mathrm{min}$ in a refrigerated centrifuge for $10 \mathrm{~min}$, and saved the supernatant at $-80^{\circ} \mathrm{C}$.

The organs for section need to cut the corresponding part, then fixed in $4 \%$ formaldehyde.

\subsection{Determination of the Relative Contents of Fatty Acids in the Brain by GC-MS}

(1) Oil saponification and separation

$300 \mathrm{mg}$ of the brain tissues was submerged by $15 \mathrm{~mL}$ solution consisted of the chloroform and methanol (2:1). Then, $3 \mathrm{~mL}$ saline was added to the homogenate. After the soluble components was fully dissolved, the mixture was centrifuged $(2000 \mathrm{rpm}, 5 \mathrm{~min})$ before the solvent was separated by rotary evaporation. Afterward, $15 \mathrm{~mL} 1 \mathrm{~mol} / \mathrm{L} \mathrm{KOH}$ - ethanol was added to dissolve the fatty substance.Then the mixture was heated in water bath at reflux for $1 \mathrm{~h}$, and evaporated again after saponification, ethanol was removed, the saponification product was dissolved into $20 \mathrm{~mL}$ water. Diethyl ether $(20 \mathrm{~mL})$ was added to the mixture, the unsaponifiable matter was extracted with a separating funnel twice. Then add $30 \%$ dilute hydrochloric acid to adjust the aqueous layer to $\mathrm{pH}$ 2.0,to make the fatty acid liberate from the saponified composition. The free fatty acids was extracted into petroleum ether $(20 \mathrm{~mL})$ twice. Then the organic solution was dried over with anhydrous sodium sulphate and petroleum ether was removed by rotary evaporation. 
(2) Hydrochloric acid methyl ester

The above mixture of free fatty acids was taken into the $100 \mathrm{~mL}$ flask, added to $\mathrm{HCl}$ methanol $(4 \%, 30 \mathrm{~mL})$, water bathing at $60{ }^{\circ} \mathrm{C}$ for $30 \sim 60 \mathrm{~min}$. After cooling, $5 \mathrm{~mL}$ water and $15 \mathrm{~mL}$ hexane was added, mixed, centrifuged, and washed with water until $\mathrm{pH}$ was adjusted to neutral. The hexane layer was extracted carefully. Na2SO4 was added to remove moisture. Then the solvent was removed through with $\mathrm{N} 2$ before it was concentrated to time by GC-MS measurement higher sensitivity can be obtained so far.

(3) Testing conditions

The fatty acid methyl esters were analyzed in a Varian chromatograph column equipped with a DB-5 silica capillary column (30 $\mathrm{mm} \times 0.25 \mathrm{~mm}$ i.d., $0.25 \mu \mathrm{m}$ film). The injector(split mode, 20:1) and FID temperature were both set at $280{ }^{\circ} \mathrm{C}$, carrier gas is nitrogen, The oven temperature was held at $120{ }^{\circ} \mathrm{C}$ for $5 \mathrm{~min}$, and then heated to $210^{\circ} \mathrm{C}$ at a rate of $10^{\circ} \mathrm{C} \cdot \mathrm{min}-1$. One microlitre samples of the eatract were injected into the instrument. For quantification purposes, the method of area normalization was used.

\subsection{Brain Tissue of Mice Sections and Staining}

Fixed brain hippocampus tissue were embedded (Beckman Counter) and sections (thickness of 4 microns) after a series of solvent treatment, and the slices were placed into $45^{\circ} \mathrm{C}$ oven for the night, HE dyeing experiments were conducted soon and observed under the light microscope.

\subsection{Statistics}

All data were presented as mean \pm SD and were analyzed using the SPSS13.0 software. One-way analysis of variance (ANOVA) and a post-hoc Tukey test were used to analyze the water maze experiment. The data were expressed as the mean values \pm SEM. Differences were considered statistically significant when a p value less than 0.05 was obtained.

\section{Results and discussion}

\subsection{Preparation of Flavonoids from Diaphragma of Walnut}

According to this process of extraction and analysis, total flavonoids from diaphragma of walnut (FDW) content is $115.54 \mathrm{mg} / \mathrm{g}$. FDW was studied in the following experiment.

\subsection{Water Maze Experiment}

Water maze experiment is now recognized as an effective detection test method of animal learning and memory ability. This test can detect and record the time associated with spatial memory of mice in the process of searching water platform.

As it could be observed from the pre-training experiment (Fig. a), significant increase of latency time to find the platform was observed in the low-dose and model group compared with normal group, while the figures for the other three groups were similar to that of the normal group. It might be the fact that the flavonoids had the potential to increase spatial memory of mice, but this effect could only be detected when the concentration reached a certain amount. Similar trend was observed in the distance mice swam to get to the platform (Fig. b). This revealed that the speed of mice in the experiment was close to each other.

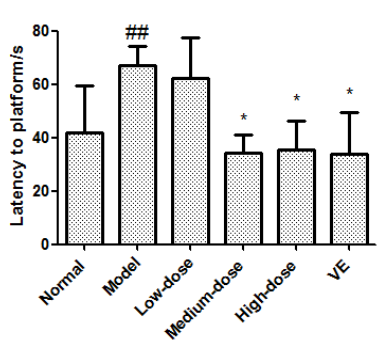

(a)

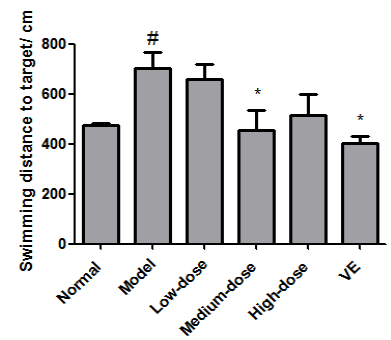

(b)

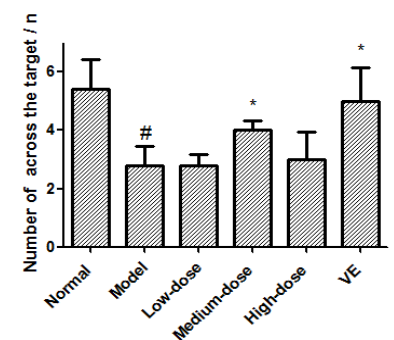

(c) 


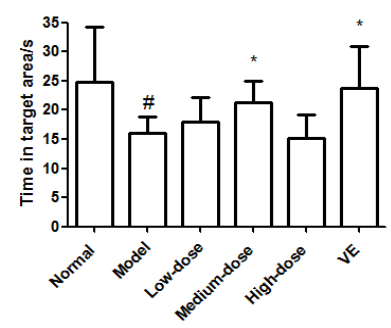

(d)

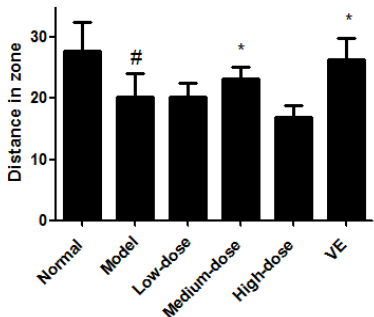

(e)

Figure 1. Effect of FDW in Hidding platform test ,Latency to platform(a), Swimming distance to target(b), in space search experiment: Number of across the target(c), Time in target area(d), Distance

in zone $(\%)(\mathrm{e})$ (All values are expressed as means $\pm \mathrm{SD}$,). compared with normal group, $\# \mathrm{P}<0.05$,\#\#P<0.01; compared with model group $,{ }^{*} \mathrm{P}<0.05,{ }^{*} * \mathrm{P}<0.01$

Poor memory and search strategy for the prior location of the platform was indicated by fewer crosses of the platform's previous location, and significantly decreased time spent searching in the quadrant of the maze which previously contained the platform. According to figure 1 generally, normal and positive control group showed stronger memory and searched strategy for the prior location with significantly more times to across the target area. The figure for the flavonoids treated group were similar to the model group except (about 3 times) for the medium-dose group (about 4 times). Similarly, more proportion of time and distance was observed in the normal and positive control group as well as infected mice' searching time and in the target quadrant approaching chance $(25 \%)$ levels. It showed that the flavonoids had the potential to enhance mice' ability to search for a prior location, but the concentration had to be controlled at a certain amount.

It could be concluded from the experiment that poor spatial memory was observed in the model group, which was an identification of the success of model building process. Experimental data showed that the floavonoids at a certain concentration could inspire spontaneous locomotor activity and exploring behavior in mice.

\subsection{Effect of FDW on Fatty Acid Composition in Brain of Mice}

The brain tissue is one of the organization with highest lipid content. Fatty acids affect brain function by adjusting membrane fluidity and membrane protein, as well as synthetic hormones or neurotransmitters. The composition and proportions of cell membrane lipid could directly affect the growth and development of some parts such as cortex and the hippocampus which are closely related to the brain's learning and memory to external material.With the increase of age, the proportion of unsaturated fatty acids could be gradually reduced by the effect of free radicals and the biofilm of unsaturated fatty acids on lipid peroxidated. The main mechanism of this process is to increase the antioxidant activity of antioxidant enzymes in vivo, reducing the level of free radicals caused by aging. In this way,the in vivo membrane lipid peroxidation is prevented to keep the integrity of cell membrane structure and function. Polyunsaturated fatty acid is the major reactant of the in vivo lipid peroxidation reaction which is the cause of aging and many diseases. For example: DHA can significantly improve brain tissue antioxidant capacity of the natural aging mice, which may associate with changes in brain fatty acid composition. Therefore, it is of great importance to analysis the composition and content of brain fatty acids and to elucidate the relationship between brain function and fatty acids . 


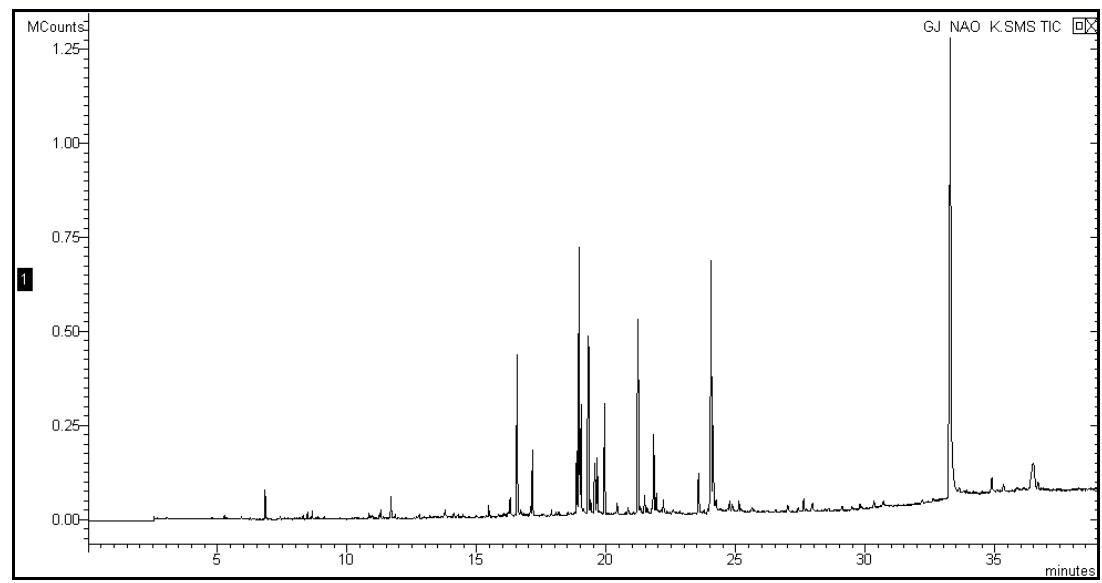

Figure 2. Chromatogram of brain fatty acids in mice

Figure 2 showed composition of brain fatty acids in mice of normal group.It could be seen that the unsaturated fatty acids of brain tissue were mainly oleic acid and EPA.

Table 1 summarized the relative content of fatty acids in each group, Compared with the control group, the difference of saturated fatty acid (myristic acid), unsaturated fatty acid such as linoleic acid, oleic acid, EPA $(\mathrm{P}<0.01)$, DHA $(\mathrm{P}<0.05)$ and palmitic acid in model group was significant $(\mathrm{P}<0.01)$.

Significant decrease was observed in the relative content of unsaturated fatty acids. Oleic acid(EPA, DHA)in the low-dose group, compared with the model group had a significant increase $(\mathrm{P}<0.05)$, but still lower than the normal group. Significant increase $(\mathrm{P}<0.05)$ of EPA content was observed in the high-dose group compared with model group. DHA can enhance learning and memory ability through the promotion of brain development and increasing neurotransmitters, while EPA, which is the key to the speed of brain reaction can activate brain neurotransmitter, speed of information processing speed and the transfer of information. This indicated that FDW played an important role in the keeping of unsaturated fatty acid contents in brain, so it could increase the mice's ability of learning, memory and preventing aging.

Table 1. Effect of FDW on relativity content of fatty acid in brain tissues of aging mice

\begin{tabular}{|c|c|c|c|c|c|c|}
\hline Fatty acid & $\begin{array}{c}\text { The } \\
\text { number } \\
\text { of } \\
\text { carbon } \\
\text { atoms } \\
\text { and } \\
\text { unsatur } \\
\text { ated } \\
\end{array}$ & $\begin{array}{l}\text { Normal } \\
\text { group }\end{array}$ & Model group & $\begin{array}{l}\text { Low-dose } \\
\text { group }\end{array}$ & $\begin{array}{l}\text { Medium-dos } \\
\text { e group }\end{array}$ & $\begin{array}{l}\text { High-dose } \\
\text { group }\end{array}$ \\
\hline $\begin{array}{l}\text { myristic } \\
\text { acid }\end{array}$ & C14:0 & $0.453 \pm 0.04$ & $0.25 \pm 0.02 \#$ & $0.25 \pm 0.01 \#$ & $0.27 \pm 0.01 \#$ & $0.32 \pm 0.01 *$ \\
\hline $\begin{array}{l}\text { Palmitoleic } \\
\text { acid }\end{array}$ & C16:1 & $0.64 \pm 0.018$ & $0.76 \pm 0.02 \#$ & $0.63 \pm 0.23$ & $0.48 \pm 0.09 *$ & $0.71 \pm 0.18$ \\
\hline $\begin{array}{l}\text { Palmitic } \\
\text { acid }\end{array}$ & C16:0 & $10.9 \pm 0.01$ & $9.83 \pm 2.67$ & $9.66 \pm 2.34$ & $7.44 \pm 0.87$ & $10.15 \pm 0.68$ \\
\hline $\begin{array}{l}\text { Linolenic } \\
\text { acid }\end{array}$ & C18:3 & $1.10 \pm 0.12$ & $1.19 \pm 0.23$ & $1.04 \pm 0.34$ & $1.03 \pm 0.11$ & $1.23 \pm 0.02$ \\
\hline $\begin{array}{l}\text { Linoleic } \\
\text { acid }\end{array}$ & C18:2 & $5.43 \pm 0.45$ & $3.33 \pm 0.98 \#$ & $3.252 \pm 0.48 \#$ & $3.67 \pm 0.78$ & $4.58 \pm 1.32 *$ \\
\hline Oleic acid & C18:1 & $15.03 \pm 2.34$ & $11.32 \pm 3.12 \#$ & $15.45 \pm 4.25^{*}$ & $14.03 \pm 1.73$ & $12.99 \pm 3.37$ \\
\hline $\begin{array}{c}\text { Elaidic } \\
\text { acid }\end{array}$ & C18:1 & $3.241 \pm 0.56$ & $3.29 \pm 0.45$ & $2.36 \pm 0.861$ & $1.99 \pm 0.84$ & $2.70 \pm 0.31$ \\
\hline $\begin{array}{l}\text { Stearic } \\
\text { acid }\end{array}$ & C18:0 & $12.09 \pm 2.34$ & $13.63 \pm 2.56$ & $12.86 \pm 0.96$ & $12.98 \pm 3.21$ & $13.55 \pm 3.71$ \\
\hline EPA & C20:5 & $12.74 \pm 3.23$ & $8.62 \pm 0.33 \# \#$ & $11.39 \pm 0.39 *$ & $11.97 \pm 0.21 *$ & $10.06 \pm 1.42$ \\
\hline DHA & $\mathrm{C} 22: 6$ & $0.25 \pm 0.04$ & $0.18 \pm 0.01 \#$ & $0.21 \pm 0.01 *$ & $0.19 \pm 0.04$ & $0.19 \pm 0.03$ \\
\hline
\end{tabular}

Note: Compared with the control group, \#\# $\mathrm{P}<0.01$, \# $\mathrm{P}<0.05$; compared with model group, $* * \mathrm{P}<0.01, * \mathrm{P}<0.01$ 


\subsection{Observation of Mice Brain slices}

Hippocampus has the structure of paleocortex and grows along the hippocampal sulcus to its internal part with the development of hippocampal tissue. It includes the dentate gyrus and hippocampus headquarters judging from the coronal section of the brain. The main task of hippocampal tissue is the temporary store of information, which is the main part in the function of memory and learning. When some information was exposed to animals, they were temporarilystored in the hippocampus. If the same information was repeatedly received for several times within a certain period, the brain regarded the information to be useful. In this way, these information were then transferred to another memory area of the brain to be permanently saved. The hippocampus area of hippocampus tissue were amplified (Fig3-3). Compared to normal group, cells of model group ranked scattered, irregularly, and there was a dicrease in the number of cells and significant fibrous voids exist in. Compared to model group, hippocampal cells in the medium high-dose group of mice of FDW of and VE groups were more concentrated with characteristic morphology of hippocampus cells, and peripheral nerve cells were densely distributed, cell size uniformed, cell gap were small, there was no obvious fibrous voids exist in. This experiment demostrated that FDW and VE can reduce the degree of oxidation of brain tissue. In some ways, FDW had antioxident properties equal to or less than VE.

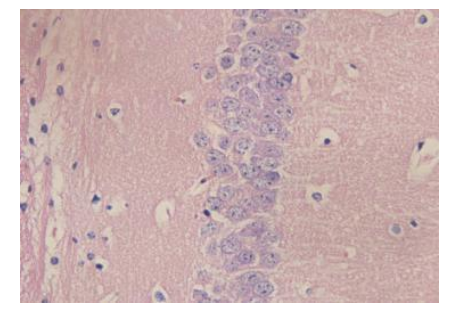

Normal group

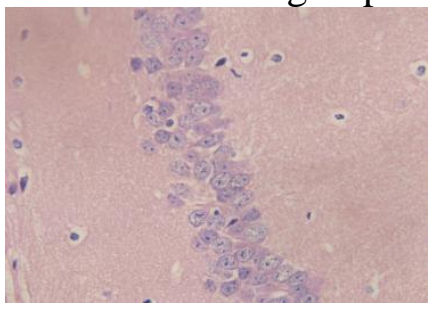

Low-dose group

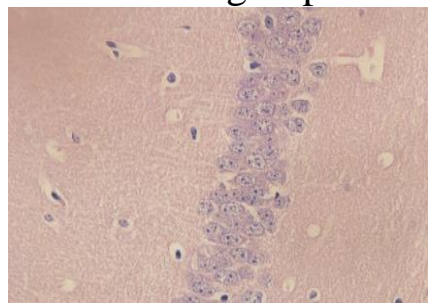

High-dose group

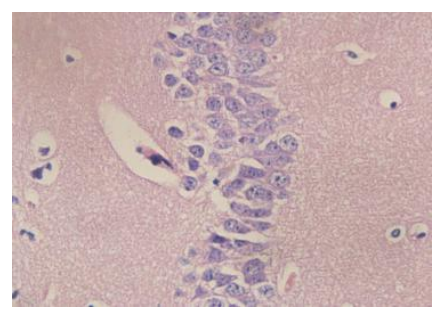

Model group

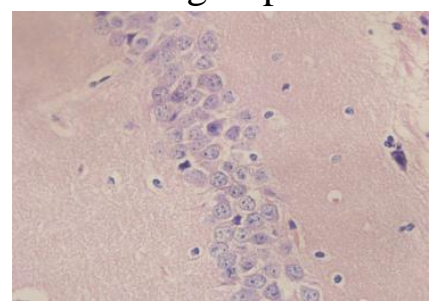

Medium-dose group

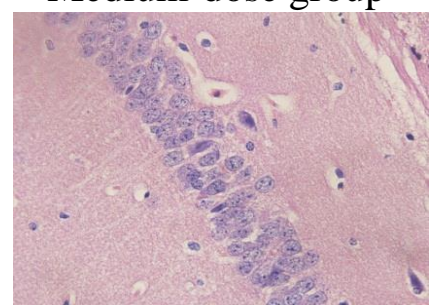

VE group

FIGURE 3. HE staining in brain hippocampus tissues of mice $(\times 400)$

\section{Conclusion}

Water maze test showed that the space exploration capacity and memory of each group of mice fed flavonoids were stronger than the aged-model mice, while the medium-dose group showed the best. The fatty acids content in mice brain tissue in each group showed that D-Galactose can reduce the content of unsaturated fatty acids in the brain, and the drug-given groups reduced the variation, increased the content of unsaturated fatty acids,particularly EPA and DHA.Observation of mice brain slices concluded that FDW had certain protection and repaired function on mice hippocampal tissue injury induced by D-Galactose.To sum up, FDW in actual production can be used as a potential source of antioxidants. 


\section{Acknowledgements}

Grateful acknowledgement is made to my supervisor Mr. Hui-ping Liu who gave me considerable help by means of suggestion, comments and criticism. His encouragement and unwavering support has sustained me through frustration and depression. Without his pushing me ahead, the completion of this thesis would be impossible. In addition, I deeply appreciate the contribution to this thesis made in various ways by my friends and classmates.

\section{References}

[1] Jose Alberto Pereira, I. O. A. S., Bioactive properties and chemical composition of six walnut (Juglans regia L.) cultivars. Food and Chemical Toxicology, 2008(46): p. 2103-2111.

[2] A. Fernández-Agullóa, E. P. M. S., Influence of solvent on the antioxidant and antimicrobial properties of walnut (Juglans regia L.) green husk extracts. Industrial Crops and Products, 2013: p. 126-132.

[3] YU Qiong-fen LIMing, N. P. Y. H., Preparation of Walnut-Shell Activated Carbon and Its Application in Environmental Protection. Chemical Industry and Engineering, 2011. 28(06): p. 63-67+73.

[4] The mechanisms of action of flavonoids in the brain: Direct versus indirect effects. Neurochemistry International, 2015: p. 126-139.

[5] Brian P. Daniels, S. R. S. S., An expanded task battery in the Morris water maze reveals effects of Toxoplasma gondii infection on learning and memory in rats. Parasitology International, 2015: p. 5-12.

[6] Dustin J. H. Van Gerven, T.F.R.W., Acute stress switches spatial navigation strategy from egocentric to allocentric in a virtual Morris water maze. Neurobiology of Learning and Memory, 2016(132): p. 29-39.

[7] LIU An- Jun, S. J. C. L., The analysis of fatty acid composition in the different animals' livers. Food Research and Dvelopment, 2007. 28(07): p. 121-124.

[8] David A. Connor, T.J.G., The role of working memory and declarative memory in trace conditioning. Neurobiology of Learning and Memory, 2016.

[9] Cécile Bascoul-Colombo, I.A.G.B., Dietary DHA supplementation causes selective changes in phospholipids from different brain regions in both wild type mice and the $\mathrm{Tg} 2576$ mouse model of Alzheimer's disease. Biochimica et Biophysica Acta, 2016: p. 524-537.

[10] The hippocampus and declarative memory: cognitive mechanisms and neural codes. Behavioural Brain Research, 2001(127): p. 199-207.

[11]JIANG Wei, Q. H. Y. D., Protection of orientin and vitexin from flowers and flower buds of Trollius chinensis on brain injury in aging mice induced by D-galactose. Chinese Traditional and Herbal Drugs, 2012. 43(07): p. 1376-1380. 